\title{
The Information Literacy Mapping on Community Empowerment Program in the Coastal Community in Semarang
}

\author{
Ana Irhandayaningsih ${ }^{*}$ \\ Department of Library Science, Faculty of Humanities, Diponegoro University, Semarang - Indonesia
}

\begin{abstract}
The aims of this research is to mapping the information literacy of the coastal community in Semarang. The mapping consists of the availability and absorption of sources of information, the pattern of society in using information and access to sources of information, and regulatory support for the city government. The second objective is to conduct information literacy mapping on women's groups in coastal communities, related to information on women's empowerment programs from the Semarang city government. In this study, there were four aspects that were mapped. The first aspect is planning activities, implementation activities, benefit taking, and evaluation. The research design used in this study is sequential exploratory, which is collecting and analyzing qualitative data then collecting and analyzing quantitative data. The research design used in this study is sequential exploratory, which consist of collecting and analyzing qualitative data followed by collecting and analyzing quantitative data. Data for this research collected in Mangunharjo Coastal Village, in Tugu City District, Semarang. Data collection is done through a focus group discussion and questionnaires, random sampling interview, and observation. The data analysis technique is done by combining quantitative analysis of data obtained from questionnaires and qualitative data analysis for data obtained from observations and, library study for mapping models. The results showed that the culture of information literacy in coastal communities in the study locations was good. In the first aspect, the availability and the use of information sources at the research location, it shows low score. Whereas in the second aspect, community activities in using information and access to sources of information, shows a bad condition. And in the third aspect, Semarang government regulation support for information literacy programs shows a good condition. Furthermore, the results of research information literacy in terms of women's empowerment programs, starting from the planning, implementation, benefit taking, and program evaluation phases, are categorized as positive.
\end{abstract}

* Corresponding author : irhandayaningsih@gmail.com 


\section{Introduction}

Semarang City has an area dominated by lowlands and coastal areas. Coastal communities generally carry out socio-economic activities related to marine resources. So that this community depends on the potential and conditions of coastal and marine resources.

Sociologically, coastal communities have different behaviours with farming communities and urban communities [1]. This difference is based on resources for the socio-economic life of every society. Coastal communities have an uncertain socio-economic life, because marine and fisheries resources are difficult to predict. In addition, these resources have a high risk of loss and produce fluctuating profits or income [2]. It also affects the nature of coastal communities, most of which are partly temporal in nature [3].

Fluctuations in socio-economic life of coastal communities, make coastal communities have minimal income and have an image of being poor [3]. This is also because coastal communities have limited access to improve the quality of human resources, education, mastering technology, expanding markets, and increasing capital.

Information literacy (reading and writing activities) is the key to improving the quality of human resources in coastal communities [4]. Information literacy is the only way to expand knowledge and skills. So that people with information literacy skills can use technology, know strategies in economic activities - including controlling the market and capital -, knowing healthy lifestyles and other knowledge [5].

The level of information literacy in a community has a high correlation with programs to improve education and community resources. Therefore, mapping is needed by using several parameters. Rachmawati in [6] conducts literacy level mapping with three parameters. The first parameter is the availability and absorption of information sources. The second parameter is access to information sources. The third parameter is government regulation support for literacy programs.

The Semarang City Government has implemented policies and programs to improve the quality of human resources in the coastal areas. The program can be categorized into three, namely programs for households, social communities, and community empowerment. The program for households aims to meet the basic needs of poor households in a coastal community. The second program, the community social program, aims to support the activities of non-productive communities in coastal communities. The third program, the empowerment program, aims to increase the productivity of coastal communities and improve the economic level of coastal communities. This program involves mentors from professionals and facilitators [7]. But in general this is not optimal and has not yet affected poverty reduction in coastal communities [8].

Most of the three programs have managers and targets for women. This is due to the greater number of female population compared to the male population, and because the male population does not have time outside his work as a fisherman. Through these programs, women have the opportunity to increase household income in addition to fishing activities. The program makes women have productive abilities and can generate income for households [9].

In order to achieve this goal, the Semarang City Government helped through an empowerment program for women in the coastal area. The program aims to open access to skills improvement, access to economic resources, and increase women's participation in 
resolving household economic problems. The large number of women is a potential capital to bring significant changes among coastal communities. To achieve this goal, women need good information literacy skills [10].

Previous studies have not produced a mapping of information literacy culture within the framework of women's empowerment programs in the coastal area of Semarang City. Therefore, the objectives of this study are :

- Mapping information literacy among women living in the coastal coastal area of Semarang City. The mapped aspects are: (i) availability and absorption of sources of information, (ii) patterns of society in using information, access to sources of information, and (iii) supporting regulations of the city government.

- Mapping information literacy aspects related to the empowerment of women living in the coastal coastal area of Semarang City. The mapped aspects include: (i) planning activities, (ii) implementation activities, (iii) benefit taking, and (iv) evaluation.

\section{Methodology}

This study uses a sequential exploratory method. The first stage in this research is collecting and analyzing qualitative data. The second stage is collecting and analyzing quantitative data. The location of the study was conducted in Mangunharjo Urban Village, Tugu City District, Semarang. This location is one of the areas that has a fishing population. Respondents in this study were selected using probability sampling techniques with simple random sampling method using a random number table. 50 samples were obtained from a total of 78 women who were wives of fishermen.

In the first stage, this study uses the focus group discussion (FGD) method, interview random sampling, observation, and through literature studies to collect data. The data analysis technique is done by combining qualitative data obtained from observation, interviews, and literature.

In the second stage, mapping the aspects of information literacy is based on qualitative FGD results and interviews, and quantitative through questionnaires. Qualitative data was obtained through FGDs and interviews with participants. Quantitative data obtained through questionnaires in the form of questionnaires. This questionnaire contains statements about information literacy in women's empowerment programs. Each statement on the questionnaire is accompanied by five choices of answers or responses that can be chosen by the respondent. The answers listed in the questionnaire refer to the Likert Scale. This questionnaire is an approach to determine the level of information literacy of each woman respondent.

\section{Results and Discussion}

The first result of this study was mapping information literacy among women living in the coastal coastal area of Semarang City. The second result of this study was mapping the information literacy aspects related to the empowerment of women living in the coastal coastal area of Semarang City. 


\subsection{Mapping information literacy among women}

This mapping is based on three aspects, namely: (i) availability and absorption of sources of information, (ii) access to sources of information, and (iii) support for government regulations.

\subsubsection{Availability and Absorption of Information Sources}

The availability and absorption of information sources in the research location is in the form of a village public library and a reading park managed by the Posdaya Group. Individual reading habits for non-student groups are still very low, namely one to two books per year. While individual reading habits for student groups have better value, which is more than ten books per year.

\subsubsection{Access and Acquisition of Information Sources}

The women (non-student groups) at the research location obtained information sources only by borrowing from the library facilities and the posdaya reading park. Whereas the group of women with the status of students has access to and ways to obtain more diverse sources of information. This group can borrow from the village library, school library, regional library, borrow from school friends, or buy at a bookstore. Non-student groups in general do not access through bookstores because of distance and costs.

The ratio of the number of women to the source of information (books / reading material) available in the village library and reading garden is (9: 1), meaning that 1 book is used by 9 people. While the ideal condition is $1: 5$ or one book is read by 5 people.

\subsubsection{Support of Government Regulations}

Semarang City government regulation related to information literacy is quite good. This is indicated by the existence of government programs for physical development and the addition of village library collections. The physical development of the library was carried out in 2014 while the addition of collections was carried out every year with funding from the regional government budget (APBD and DAK). What is still lacking is the absence of regional legislation or regulations that specifically regulate the development of a weak reading culture, or the regulation of the role of libraries in supporting the achievement of a culture of literacy.

\subsection{Mapping information literacy among women related to empowerment programs}

This mapping is based on four aspects, namely: (i) planning activities, (ii) implementation activities, (iii) program benefits, and (iv) evaluation. Mapping each aspect is measured by a questionnaire. The questionnaire given to respondents was in the form of a closed statement regarding Literacy of community information in the implementation of women's 
empowerment programs at the research sites. The choice of answers to the questionnaire refers to the Likert scale. The weight of each answer choice is as table 1.

Table 1. Weight of each answer choice

\begin{tabular}{|l|c|c|}
\hline \multirow{2}{*}{ Answer Choice } & \multicolumn{2}{|c|}{ Score } \\
\cline { 2 - 3 } & Positive Statement & Negative Statement \\
\hline Strongly disagree & 1 & 5 \\
\hline Disagree & 2 & 4 \\
\hline Unsure & 3 & 3 \\
\hline Agree & 4 & 2 \\
\hline Strongly agree & 5 & 1 \\
\hline
\end{tabular}

The results of the Likert score calculation of all respondents (50 respondents) were then analyzed by descriptive models based on quartiles. This model classifies the results of the score calculation into levels as follows :

Table 2. Range total score categorization

\begin{tabular}{|c|l|}
\hline Range Score & \multicolumn{1}{|c|}{ Category } \\
\hline $201-250$ & Very Active \\
\hline $151-200$ & Active \\
\hline $100-150$ & Inactive \\
\hline $50-100$ & Not active \\
\hline
\end{tabular}

\subsubsection{Information Literacy in Decision Making / Planning}

This aspect is measured through four indicators, namely: a) Information on women's empowerment programs obtained through government instruments (kelurahan or RT / RW), b) People get the information and can understand, c) People find out more about women's empowerment programs, d) The community has provided input on ideas / ideas in women's empowerment programs.

The results of the questionnaire showed that the women who were respondents in this study had a good level of information literacy in women's empowerment decision making / planning programs. The result of calculating the likert score for this indicator is 190. Based on the categorization described in Table 2, this result is at active level.

\subsubsection{Literacy of Community Information in Program Implementation}

This aspect is measured through three indicators, namely a) understanding the information provided during program implementation, b) being able to answer questions given during program implementation, and c) ever assisting in the implementation of the program, such as being an administrative officer or cadre. 
The results of the questionnaire showed that the women who were respondents in this study had a good level of information literacy during the implementation of women's empowerment programs. The result of calculating the likert score for this indicator is 210 . Based on the categorization described in table 2, this result is at a very active level.

\subsubsection{Literacy of community information in taking benefits}

This aspect is measured through three indicators, namely: a) women experience increased knowledge and skills, b) women have taught skills acquired during the program to families or the environment, and c) women have economic benefits from the skills acquired.

The results of the questionnaire showed that the women who were respondents in this study had a good level of information literacy to benefit from women's empowerment programs. The result of calculating the likert score for this indicator is 192. Based on the categorization described in table 2, this result is at active level.

\subsubsection{Literacy of Community Information in Program Evaluation}

This aspect is measured through three indicators, namely: a) Never give advice to program managers, b) Never give a complaint about the implementation of activities to program managers, c) Never help program managers in preparing reporting activities.

The results of the questionnaire showed that the women who were respondents in this study had a good level of information literacy to take the evaluation of women's empowerment programs. The result of calculating the likert score for this indicator is 180 . Based on the categorization described in table 2, this result is at a level.

This result also shows that the women in the research locations have good information literacy skills, supported by high interest and enthusiasm to develop themselves without depending on the lack of available sources of information.

\section{Conclusion}

The results showed that the culture of information literacy in coastal communities in the study locations was good. In the first aspect, the availability and the use of information sources at the research location, it shows low score. Whereas in the second aspect, community activities in using information and access to sources of information, shows a bad condition. And in the third aspect, Semarang government regulation support for information literacy programs shows a good condition. Furthermore, the results of research information literacy in terms of women's empowerment programs, starting from the planning, implementation, benefit taking, and program evaluation phases, are categorized as active and very active level. 


\section{References}

1. Coleman, James S. Foundations of Social Theory. Cambridge, Mass: Belknap Press of Harvard University Press (1990)

2. Ambo, T H . Management of Coastal and Marine Ecotourism. Surabaya Brilliant International. (2011)

3. Maulana F, Rikrik R, Role of fisherman's wife in household improvement (case study in Penjajab Village Pemangkat District Sambas Regency) J. of Socioekonomic Marine and Fisheries 10 (2) pp. 241-249 (2015)

4. Adam, C.; Buetow, S.; Edlin, R.; Zdravkovic, N. and Heyhinger, J. A Collaborative Approach to Integrating Information and Academic Literacy into the Curricular of Research Methods Course. The Journal of Academic Librarianship 42(3), 221-231 (2016)

5. Zinn, S, Stilwell, C, \& Hoskins, R. Information Literacy Education in the South African Classroom: Reflections from Teachers' Journals in the Western Cape Province. Libri 66(1), 31-34 (2016)

6. Rachmawati, T. S. Study on Mapping of Information Literature Culture in South Coastal Communities West Java Province. Record And Library Journal 4(1), 1-6 (2019)

7. Agung U, Titin H H, Model of empowering poor women through training of local potentialbased entrepreneurship in District of Wedi Klaten Regency J.of Humanities Research 19(2) pp154-167 (2014)

8. Nugroho, M. Fishermen empowerment in Pasuruan District : Study of development of human resource empowerment model in coastal area. J.of Food Technology 6(1) pp 1926 (2015)

9. Zakiyah, Empowerment of women by Lajnah women J. of Assessment of Religious Social 17 p 442010

10. Yusup PM, Saepudin E, Information Literacy Practices In The Process Of Lifelong Learning Jurnal Kajian Informasi dan Perpustakaan 5 (1), 79-94 (2017) 